\title{
AS NOVAS E VELHAS ESPERANÇAS DE UMA COMUNIDADE EM FLORIANÓPOLIS
}

\author{
Francisco Canella*
}

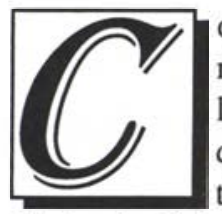

omunidade de origem migrante, com passado militante e pobre. Um lugar que reúne essas características, em uma cidade como Florianópolis', pode nos colocar um conjunto de importantes questionamentos: de um lado, tal tipo de comunidade, tanto pela sua própria existência como pelas lutas que promoveu, aponta as contradições de um discurso acerca do desenvolvimento urbano de Florianópolis; de outro, permite a compreensão de uma peculiar dinâmica social estabelecida em uma comunidade de periferia urbana. É esse segundo aspecto que o presente artigo pretende abordar: como, no contexto de lutas que denunciavam um discurso e apontavam alternativas para a cidade, foram produzidas específicas sociabilidades ${ }^{2}$, e em que estado se encontram hoje. Examinar esse processo, considerando suas rupturas e permanências, é o objetivo desse artigo.

\section{A LUTA}

A comunidade em questão chama-se Nova Esperança, e é resultado de uma ação organizada pelo Movimento dos Sem Teto no início dos anos 90. O próprio nome, surgido no calor das lutas travadas com o poder público, indica a presença de um projeto alternativo ao existente na cidade. Após a ocupação de um terreno em bairro de classe média de Florianópolis, vários integrantes do movimento dos sem-teto conseguiram, através de um processo de negociação com a Prefeitura de Florianópolis, ser assentados no bairro Monte Cristo. A partir daí, com base na organização coletiva já estruturada desde a preparação das primeiras mobilizações do grupo e com base no apoio recebido de ONGs, as 49 famílias que compunham o movimento construíram suas casas em regime de mutirão.
A comunidade era formada por migrantes recém chegados à cidade, cujo destino comum seria a condição miserável de viver em uma favela - não habilitados profissionalmente, com baixos níveis de instrução, despreparados para empregos urbanos melhor remunerados - e por famílias que já viviam há longa data na cidade (mas também com passado migrante) e que passaram a constituir uma parcela empobrecida da população, que já não suportava pagar aluguéis. Igualmente significativa era a presença de pessoas nascidas na própria cidade ou em municípios vizinhos ${ }^{3}$. Essa pobreza que se encontra-

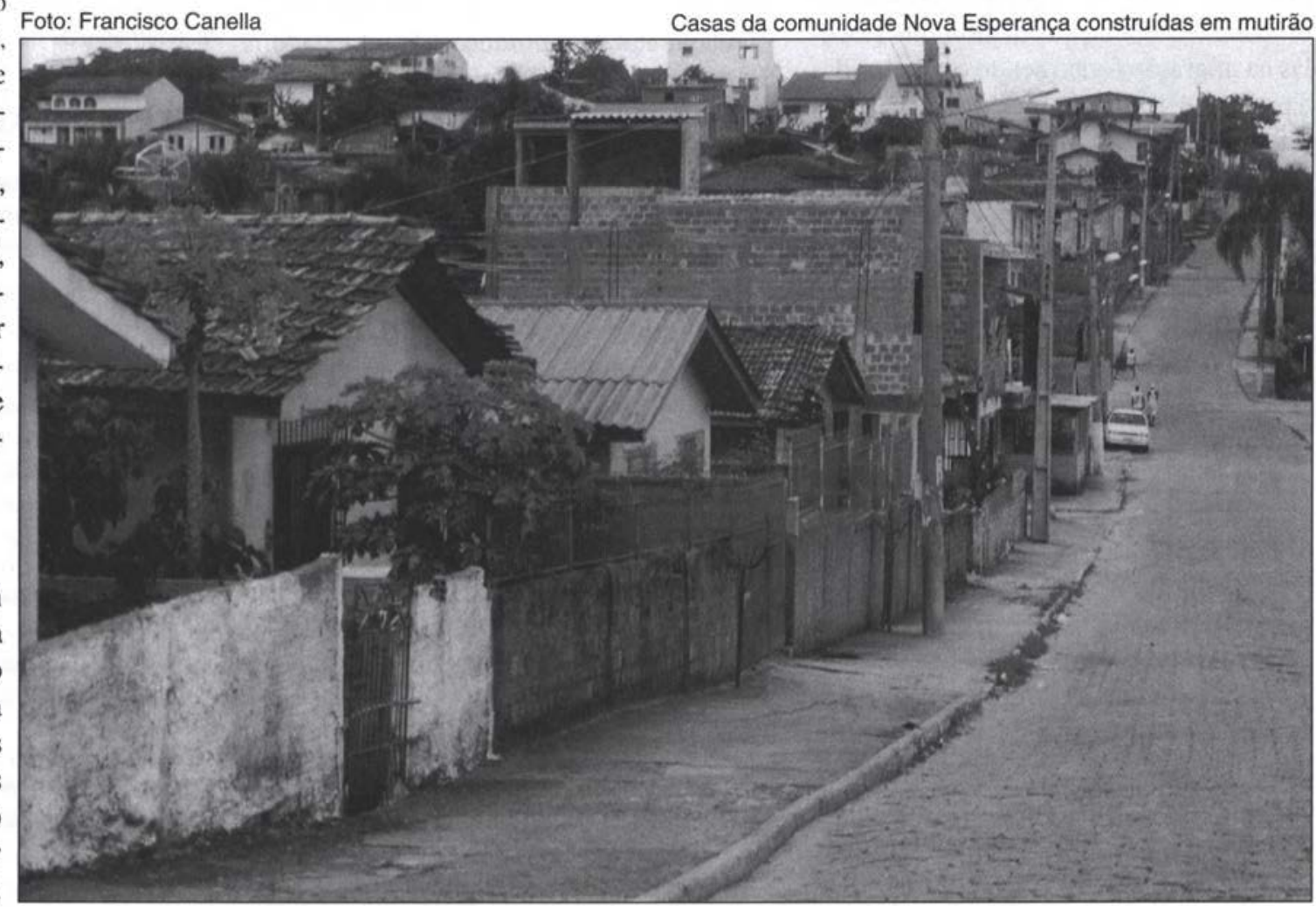


va dispersa passou a se aglutinar em torno de uma instituição de finalidade filantrópica, o Centro de Apoio e Promoção do Migrante (CAPROM), ligado à Igreja Católica. Em pouco tempo, e sob influência do discurso da Teologia da Libertação, - CAPROM radicalizou a sua prática, organizando ações coletivas para pressionar autoridades, até chegar ao ponto de promover ocupações de terrenos.

$\mathrm{Na}$ época, o movimento foi considerado vitorioso. Isso, por dois motivos: um ligado às disputas simbólicas em torno do destino da cidade; outro, relaciona-se às conquistas políticas e organizativas da coletividade, que lança a discussão ao terreno da sociabilidade.

\section{FLORIANÓPOLIS E O QUE UMA VIA PODE EXPRESSAR}

Foi a partir da década de 80 que Florianópolis vivenciou um crescimento populacional mais acentuado, com a absorção de novos moradores, vindos tanto do interior como de estados vizinhos. Esse crescimento urbano se deu articulado a um discurso, bastante presente na mídia local e ligado àqueles que tinham como projeto uma metropolização da cidade ${ }^{4}$, que pretendia divulgar a cidade como um lugar tranqüilo, com ares provincianos, ilha cercada por belas praias e com uma natureza exuberante. Assim, o ponto de partida dessa metropolização seria a "vocação turística" da Ilha de Santa Catarina. Se a simples presença de migrantes pobres na cidade já denunciava a existência de uma outra realidade, em oposição a um discurso oficial, a ação organizada desses novos e indesejados moradores politizava a discussão sobre o futuro da cidade, prejudicando todo um projeto das elites locais.

Essa incômoda visibilidade pode ser ilustrada com uma matéria, publicada num órgão da grande imprensa nacional (o jornal Folha de São Paulo), intitulada "Florianópolis tem mais miséria que Rio e São Paulo". O jornal apresentava dados (colhidos junto ao IPEA) que revelavam outra Florianópolis: 11,9\% da população vivendo em situação de miséria, contra $6,3 \%$ em São Paulo e $10,2 \%$ no Rio de Janeiro. E citava a matéria: "Uma das maiores favelas é uma espécie de cartão de visi- tas para quem chega à capital catarinense. São centenas de barracos agrupados ao longo da Via Expressa, avenida de quatro pistas que liga a rodovia BR-101 ao centro da cidade" (Mallmann, 1994, p.9).

Aqueles que procuravam associar o seu desenvolvimento à potencialidade turística de suas belezas naturais não podiam conviver com a exposição, com a grande visibilidade da miséria. Recentemente, durante a atual gestão foram feitas, nas margens da Via Expressa e na parte externa de uma dessas favelas, algumas construções inspiradas no projeto Cingapura. Foi uma clara tentativa de esconder esse indesejado cartão postal da cidade que se pretende capital turística do Mercosul.

Localizada nessa região, próxima à Via Expressa (mas não nas suas margens, local considerado pelo próprio movimento como inadequado), as conquistas da Nova Esperança representavam uma vitória na disputa em torno dos significados que se pretendiam estabelecer na e sobre a cida$\mathrm{de}^{5}$. O movimento conseguiu transferir alguns dos ocupantes das margens do asfalto para a área da Nova Esperança. Com isso, garantiu condições dignas de habitação e, ao mesmo tempo, afrontou aqueles setores que não desejavam sua presença em tal área da cidade.

Outro aspecto, que se liga a esse e que é bastante ressaltado pelas lideranças, diz respeito à composição do grupo, e o que isso denunciava. Como já foi colocado anteriormente, não era apenas um grupo de migrantes vindos diretamente do campo, empurrados para a cidade por ilusões ou promessas de uma vida mais fácil. $\mathrm{O}$ problema de tal miséria, exposta pela Via Expressa ao olhar de todos que chegavam em Florianópolis, não podia ser atribuído apenas ao impacto de levas de migrantes provenientes do interior do estado. Os que moravam em Florianópolis há longa data, denunciava o processo que resultou na Nova Esperança, também não tinham mais o seu lugar, tornavam-se excluídos do progresso da cidade. É nesse contexto que deve ser entendido o porquê da positividade atribuída a essa comunidade - o que se refletiu sobre os moradores: era comum, entre lideranças e assessorias ligadas aos movimentos sociais, ser mencionada a "auto-estima" elevada dos mora- dores da Nova Esperança.

\section{A COMUNIDADE NOVA ESPERANÇA}

Se retrocedermos dez anos, veremos uma comunidade que construiu uma representação de si mesma como vitoriosa diante das tarefas que se propôs como movimento organizado, forte porque unida e feliz pelas condições alcançadas. O próprio nome escolhido pelos moradores para sua comunidade tem uma clara conotação positiva: Nova Esperança. Tais significados foram estabelecidos no contexto maior de uma cidade que crescia (e continua crescendo) de um modo abrupto e desordenado. As conquistas desse movimento representavam, antes de mais nada, a visibilidade de um processo que não era apresentado por um discurso oficial acerca da cidade.

$\mathrm{O}$ fato de ter surgido de um processo de lutas demarcou uma significativa diferença com relação às outras comunidades. A Nova Esperança em seu início foi marcada pela união coletiva. O morar coletivamente faz parte de uma história compartilhada - os encontros foram simultâneos: o descobrir-se como uma coletividade se deu na própria luta para existir como uma comunidade. Havia um objetivo comum. Daí a força que o termo comunidade adquiriu entre os moradores. Em suas memórias, há uma clara delimitação entre um passado e um presente. O passado é de lutas: glorioso pelas suas conquistas, memorável pelas suas aventuras, gostoso pelo sentimento de comunidade. Esse passado estendeu-se até o final do mutirão para a construção das casas e às últimas negociações em torno da urbanização do bairro. Em contraposição a esse tempo, vem uma nova realidade: o hoje, carregado de significados negativos, como podemos verificar nesta fala de uma antiga liderança:

"A comunidade hoje está péssima. No começo nós éramos muito unidos, agora não vê mais reunião, não vê mais festa nenhuma, eu acho que a comunidade é cada um pra si mesmo. Era tão bom antes, porque tinha festa, a gente participava de encontro, a gente ia passear, agora oh" (Dolzan, 2000, p.44).

Dado o processo de luta - e a especifi- 
cidade da conjuntura política da cidade a Nova Esperança obteve importantes conquistas em termos de equipamentos urbanos, a ponto dos moradores não se considerarem favelados - o que, por exemplo, é diferente com a comunidade vizinha, a Chico Mendes, que é freqüentemente chamada de "favela Chico Mendes". Possui água encanada e luz (sem ligações clandestinas), as casas têm área construída de 40,6 metros quadrados, as ruas são calçadas, existe serviço de coleta de lixo e até mesmo uma pequena praça. Tudo isso, resultado das lutas coletivas, cuja conseqüência foi uma auto-imagem da comunidade bastante positiva. Nunca é chamada de favela, nem por quem nela mora, nem pelas pessoas de fora. As lutas mudaram um destino comum: deveriam ser favelados, mas não o são.

\section{A COMUNIDADE UNIDA}

Mais do que simplesmente atender a demandas sociais, o projeto que organizava a Nova Esperança não só tinha como horizonte uma nova sociedade mas, principalmente, organizar novas relações entre os sujeitos, no aqui e agora, pautada por princípios solidários, coletivos e democráticos. A prática do bairro deveria ser organizada pelo político. A começar pela própria auto-definição da coletividade como uma comunidade. Logo da ocupação, evitaram fundar imediatamente uma associação de moradores, pois essa só deveria acontecer respeitando o próprio processo de amadurecimento político da comunidade. Conforme colocava um membro do CAPROM: “... é um período que eles têm de realmente se tornar comunidade, não é? Porque até ali é um grupo que se agrupou e cada um de um lado..." (Canella, 1992, p.92).

A Associação de Moradores, espaço político por excelência, teria que, para existir, traduzir os laços sociais estabelecidos, que deveriam superar o "cada um de um lado". É importante observar que o nome escolhido para uma das comunidades organizadas pelo movimento é Nova União. Essa união política teria como objetivo manter a luta. Haveria uma comunidade cuja sociabilidade seria pautada pela organização permanente em prol de seus objetivos:

"É porque a luta nunca pára, nunca vai acabar: Mesmo que a gente consiga o terreno, sempre vai ter coisa pra gente conseguir. Agora tem a creche... então sempre vai ter isto aí: tem creche, tem praça, tem um movimento aqui dentro da comunidade... tem alfabetização... Então, tudo isso ai que pode entrar, depende de uma luta que vai continuando, que vai crescendo..." (Canella, 1992, p.91).

E a organização deveria ser de todos. Havia a consciência de que a Associação de Moradores poderia significar uma centralização do poder nas mãos de poucos. Procurando evitar este risco, propuseram uma forma de organização alternativa à Associação, as Comissões de Moradores. De acordo com este modelo, a comunidade passaria a reunir-se por quadras, garantindo, com isso, a efetiva participação do conjunto dos moradores. Apostavam que a relação de vizinhança, tanto em razão de vivenciarem problemas comuns como pela convivência cotidiana, favoreceria a participação política.

Em resumo, a condição para a existência de uma comunidade era a união, que tinha como objetivo a luta política, a qual teria que ser democrática. Eram esses os elementos ordenavam a prática que tornava possível a vida do bairro. Eé dessa vida comunitária que os moradores hoje sentem saudade.

\section{FICOU A COMUNIDADE "NA ESPERANÇA"?}

Passados quase 10 anos, que dinâmica encontramos? Que trajetória foi construída ao longo desse período e que marcas ainda se fazem presente, como um legado de sua origem em lutas sociais? Como se encontra hoje a comunidade, diante de um processo de crescimento urbano e de exclusão social?

Várias mudanças ocorreram e se apagaram muitos dos traços de uma sociabilidade pautada pelas mobilizações coletivas e pelo sentimento de pertencimento a uma comunidade. No entanto, considera-se que as relações hoje estabelecidas entre os diferentes atores, mesmo que configurando uma nova realidade, podem ser analisadas como portadoras da história dessa comu- nidade e como reveladoras de possíveis caminhos para o futuro.

Mesmo não sendo favelados, as condições de vida não se alteraram (pelo menos para a grande maioria dos moradores). Se o processo coletivo garantiu habitação digna, não mudou o nível de renda, não mudou o grau de escolaridade e continuaram os antigos sem-teto a viver numa cidade que cresce sem evitar exclusões. Aliás, aumento da atividade turística não implicou em melhoria das condições de vida da população empobrecida. Talvez em razão de uma memória que remete ao passado todas as positividades, os moradores da NE ao definirem o presente, o fazem resignificando a experiência de viver coletivamente, agora conferindo-lhe uma série de atributos negativos: o desemprego, a falta de união, a pobreza, a violência, as drogas. Se um passado os diferencia, o presente os iguala às outras comunidades empobrecidas.

\section{NOVAS SOCIABILIDADES - QUANDO A CASA CAI}

A decepção com a não permanência do projeto de lutas desencadeou uma nova dinâmica na comunidade. Para além da união coletiva, outros elementos de um passado anteriormente não manifestados estão sendo incorporados a essa dinâmica. Com a acomodação, ou com a estabilização da comunidade, voltam à cena. E a sociabilidade que se dá nesse novo momento não é mais organizada por projetos políticos coletivos.

Emblemático dessa situação é o estado em que se encontra a casa comunitária. Quando ocorreu a ocupação dos 50 lotes em que foi dividida a área para o assentamento das famílias, um deles ficou reservado à construção da casa comunitária, que serviu, durante vários anos, para as reuniões da Associação e outras atividades de cunho comunitário (como a Oficina do Saber - um trabalho de reforço pedagógico mantido por uma ONG). Atualmente, a Associação encontra-se sem diretoria, pois não foram realizadas as eleições. Como conseqüência, a casa deixou de ser um ponto de referência da organização comunitária. Aos poucos, foi sendo abandonada pelos moradores. Bastante deteriorada, 


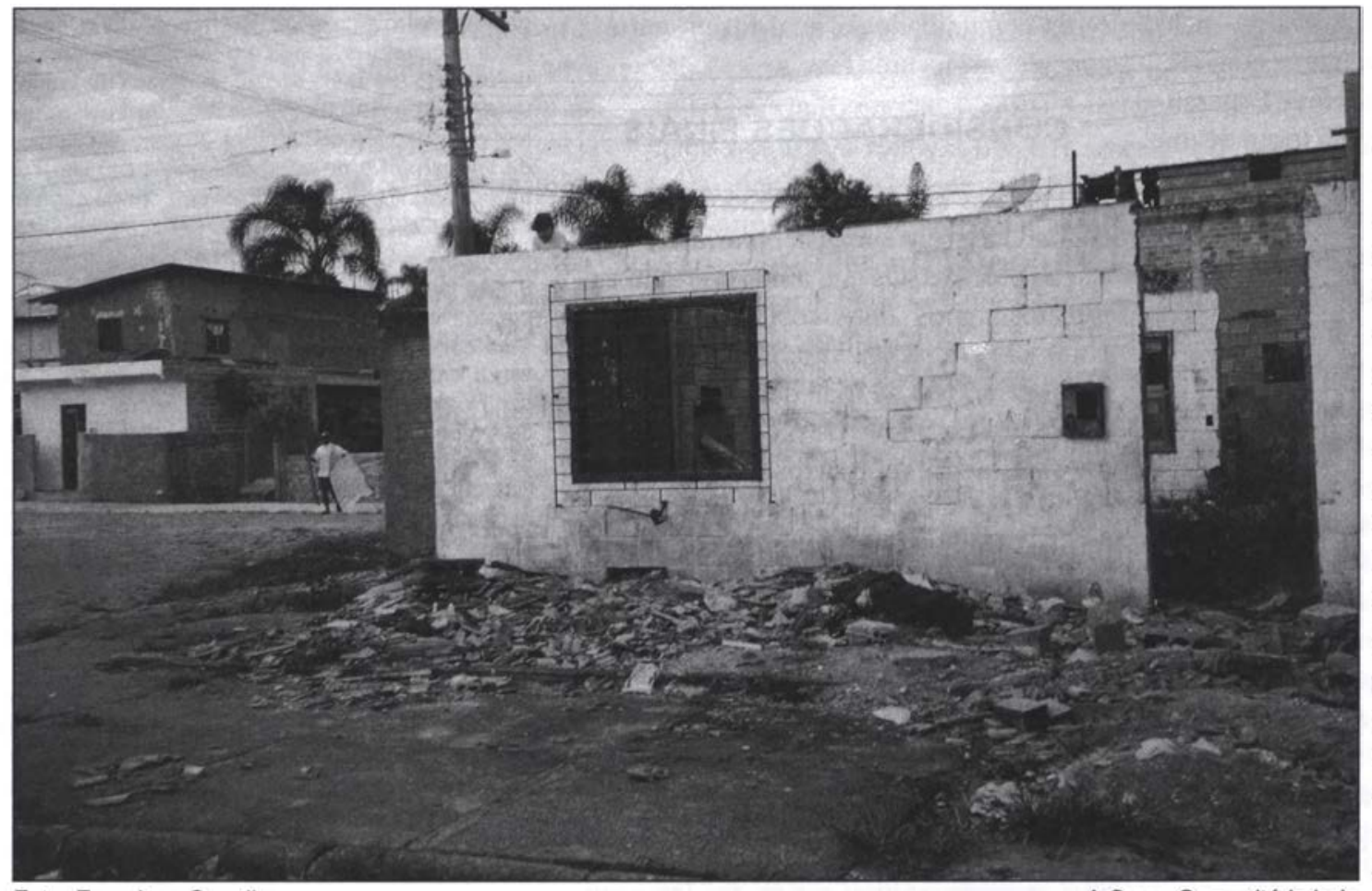

Foto: Francisco Canella

foi destelhada com a promessa, por parte de um funcionário da Prefeitura (e candidato a vereador), de ser reformada. Até hoje, permanece sem telhado e o mato tomou conta.

Mais do que uma metáfora, a situação da casa traduz uma trajetória coletiva. Seus usos revelam as mudanças ocorridas: primeiro, deixou de aglutinar em razão de finalidades políticas, passando a servir para missas mensais e para a realização de algumas oficinas que, aos poucos, foram esvaziando-se. A entrada na comunidade de pastores evangélicos (os "crentes") - cujo discurso não guarda qualquer familiaridade com aquele discurso mobilizador dos setores da Igreja Católica - também implicou num novo uso da casa: os cultos ali se realizavam, vários na semana, e, ironicamente, perturbavam principalmente a casa da primeira presidente da comissão de moradores.

Uma parcela da nova geração, constituída por aqueles que eram ainda crianças quando das primeiras ocupações, é usuária de drogas. Abandonada, a antiga casa comunitária tem servido como ponto de encontro desses jovens. Alguns utilizamna para, por vezes, ali pernoitar. A casa começa a ser identificada pela vizinhança como um lugar perigoso, impróprio, até mesmo uma ameaça para suas crianças, pois lá ficam jogadas seringas sujas. Assim, o local tornou-se espaço de numa transgressão e, como tal, afeta aquilo que Mayol (1996, p.50) define como a transparência social do bairro: "O bairro é um universo social que não aprecia muito a transgressão; esta é incompatível com a suposta transparência da vida cotidiana, com sua imediata legibilidade". Na leitura dos moradores, tal fato torna a comunidade inviável: "Não é possível viver desse jeito", diz uma moradora, referindo-se ao problema.

O episódio do destelhamento da casa - ápice do processo - também é revelador dos novos tempos: o tipo de negociação que se deu só foi possível graças às relações estabelecidas entre a última direção eleita (classificada como "de direita" pelos próprios moradores) e a atual administração municipal, considerada pelos movimentos populares sua "inimiga histórica". Vítimas de uma promessa eleitoral, vários dos antigos moradores que lideraram a comunidade não têm mais a pretensão de rearticular a associação: tomar tal iniciativa pode resultar em conflitos com os seus vizinhos. Em nome de um cotidiano tranqüilo, abdicam do espaço político. O cotidiano se despolitiza. É como se a comunidade ficasse politicamente "destelhada".

Sem representação e coletivamente desarticulada, os moradores da Nova Esperança têm problemas com a atual gestão municipal. Cobranças de IPTU e de prestações pelas casas estão entre as principais reclamações no plano político. Não havendo quem os represente politicamente, as soluções são tomadas no plano individual. Até mesmo aquelas decisões que mereceriam respostas coletivas (e aqui, mais uma vez, a casa comunitária): a atual gestão resolveu cobrar judicialmente o IPTU de quem não se enquadrou na categoria de isentos. Tal cobrança recaiu, inclusive, sobre o prédio da casa comunitária. Como foi construído no lote localizado junto à casa da primeira presidente da Comissão de Moradores, a Prefeitura não hesitou em cobrar dessa pessoa as referidas dívidas. Essa moradora, antiga liderança do movimento, não recebe qualquer apoio ou solidariedade dos seus vizinhos. Nesses novos tempos da comunidade, não há, para ela , qualquer cobertura legal, política ou comunitária. Os antigos sem teto estão, de certo modo, novamente destelhados. A perda do valor coletivo fica evidente na solução pensada por alguns moradores para o problema da casa comunitária. Outrora símbolo da união coletiva, a alternativa para ela proposta agora é estritamente individual: alguns moradores tentam colocar parentes e/ou amigos seus naquele lote.

A "convenção coletiva tácita" que torna um bairro possível, a que se refere Mayol (1996, p.47), é lida pelos moradores através de novos códigos e de novos comportamentos. Não é mais o político (entendendo-o como mobilização coletiva da comunidade em torno de objetivos comuns, dizendo respeito a uma atuação na esfera pública) o elemento aglutinador. $\mathrm{Na}$ verdade, não existe mais um elemento que aglutine a comunidade. É possível falar em 
diversas (e dispersas) comunidades - pelo menos se tivermos em mente o conceito de comunidade original da Nova Esperança: a coletividade reunida em torno de um objetivo comum. São tantas as comunidades quantas as naturezas das relações estabelecidas entre os seus membros: podem ser pela religião, podem ser pelas drogas, pelo local de origem, ou pela proximidade geográfica, pelo parentesco, etc. $\mathrm{O}$ que redefine as relações entre os moradores são tanto elementos de uma antiga sociabilidade(as relações familiares de parentesco, ou por local de origem, ou étnica), agora melhor visualizados em razão da despolitização do cotidiano, como os novos elementos incorporados à dinâmica da comunidade (como aquela parte da juventude que se aglutina através das drogas).

Pode-se verificar, por exemplo, no próprio modo como ficou organizada a vizinhança, a presença de elementos de uma sociabilidade que é até mesmo anterior à constituição da comunidade. É o caso do elemento étnico: boa parte da população negra, proveniente dos morros que circundam o centro da cidade e da parte continental de Florianópolis, habita "os fundos" da comunidade, e estabelece entre si laços mais fortes de sociabilidade. Do mesmo modo, é comum os moradores identificarem-se mutuamente pelo local de origem: "o pessoal do Oeste", "os lageanos", "os nativos"...

Nas novas gerações, mesmo entre aqueles que não são usuários de drogas, não se verifica uma contrapartida no sentido da mobilização comunitária. Também constroem uma imagem negativa da comunidade: como pobre, violenta, sem lazer $\mathrm{e}$ sem perspectivas.

Podemos ainda incluir aqueles casos em que a sociabilidade é apenas negativa (ou simplesmente não é): os novos moradores, em sua maioria, não criam laços de sociabilidade com os seus vizinhos, recusando qualquer tipo de "vida comunitária". Das 10 novas famílias que compraram as casas de antigos moradores (e que, portanto, não compartilharam de qualquer experiência coletiva no passado), é comum o comportamento de retraimento diante da comunidade, e o desejo de sair dela. Não se misturam. E até mesmo envergonham- se da comunidade da qual fazem parte consideram-na uma favela.

\section{CONSIDERAÇÕES FINAIS}

Passada uma década, encontramos a comunidade sem qualquer entusiasmo para a ação coletiva. Os que ainda apostam em projetos como o da Associação de Moradores são em reduzido número. Parte deles inserindo-se na rede clientelista tradicional (como foi o caso da última gestão) e, desse modo, motivados por vantagens individuais. Os que procuram recuperar as formas originais de mobilização, que tinham como mote a "união comunitária" e como estratégia o enfrentamento com o poder público, vêem-se em número cada vez mais reduzido e reconhecem o limite da sua proposta. Ressentem-se do presente e enaltecem o passado - como nos diz uma outra moradora: "....antes o pessoal, todo mundo ajudava todo mundo, porque olha, a gente ocupou assim, foi feito um barraco lá em cima, umas casinhas de madeira (..) se alguém começasse a botar uma tábua todo mundo ajudava, hoje em dia se tu cair no meio da rua ninguém nem estende a mão" (Dolzan, 2000, p. 44).

No entanto, o que torna esse ressentimento tão forte e tão presente na fala dos moradores é a memória de um tempo melhor, quando a comunidade era outra. A leitura que fazem dos elementos de ruptura que pautam a sociabilidade presente, como por exemplo, o uso de drogas e a violência, traduz-se numa percepção da vida cotidiana da comunidade como impossivel. Existe, assim, um elo de continuidade com o passado: o que define as impossibilidades do presente é justamente a possibilidade de viver (por já ter vivido) em uma outra comunidade. E aí, talvez. resida alguma esperança.

* Francisco Canella é mestre em Sociologia Politica pela UFSC e prof. da Universidade do Estado de Santa Catarina-UDESC.

\section{NOTAS}

1. Este artigo é resultado de uma pesquisa em andamento, intitulada "Educação e cultura em uma comunidade de periferia de Florianópolis", desenvolvida na UDESC.

2. As relaçōes de sociabilidade estabelecidas no interior de uma comunidade são tratadas nesse artigo no sentido atribuido por Pierre Mayol (1996) à "prática do bairro", como a inserçāo que torna possivel, através de um sistema de obrigações e reconhecimentos, a vida em um bairro, entendendo-o como um meio social. "A prática do bairro é uma convenção coletiva tácita, não escrita, mas legivel por todos os usuários através dos códigos da linguagem e do comportamento (...) Um contrato, portanto, uma 'coerçāo' que obriga cada um para que a vida do 'coletivo público'- o bairro seja possivel para todos." (p. 47).

3. "As familias desta comunidade, antes da ocupação, residiam $65 \%$ em Florianópolis, 30\% na área conurbada e $5 \%$ em outro municipio. Todavia, a origem destas familias é: $32,60 \%$ do sul e centro do Estado; $16,27 \%$ de Florianópolis; $11,27 \%$ da região da Grande Florianópolis; $10 \%$ do Paraná; $8,76 \%$ do Rio Grande do Sul; $8,76 \%$ do oeste do Estado; $5 \%$ do norte do Estado; $3,72 \%$ do vale do Itajaí e 3,73\% de outros estados (Dolzan, 2000:14). O processo migratório em direçāo a Florianópolis confirma as análises de Durham (1973) no estado de Sāo Paulo: a maioria dos migrantes não veio diretamente do campo para a realidade urbana da capital.

4. Márcia Fantin (2000: 17) identifica esse grupo de atores como sendo constituido "pelo empresariado da indústria do turismo e do comércio, administradores públicos e agentes politicos locais vinculados a partidos conservadores".

5. Com relação a essa questão, Márcia Fantin, em seu livro "A cidade dividida" (2000), adota a noçāo de disputas simbólicas para analisar as disputas e os discursos em torno do que seria a "vocação" de Florianópolis -transformar-se em metrópole ou manter-se como cidade de porte médio.

\section{REFERÊNCIAS BIBLIOGRÁFICAS}

AZIBEIRO, Nadir \& PERASSA, Ivone

(1992) O papel educativo dos movimentos sociais: a experiência da "Nova Esperança". Florianópolis, texto digitado.

\section{CANELLA, Francisco}

(1992) A UFECO e o Movimento dos SemTeto: práticas instituintes nos espaços políticos da cidade. Florianópolis, Dissertação de Mestrado em Sociologia Política, Universidade Federal de Santa Catarina.

DOLZAN, Janiane Cinara

(2000) Caminhos/Imaginário/Conquistas. 0 Movimento Sem Teto e a Comunidade Nova Esperança. Florianópolis, Trabalho de Conclusão do Curso de História, FAED/ Universidade do Estado de Santa Catarina.

DURHAM, Eunice Ribeiro

(1973) A caminho da cidade: a vida rural e a migraçāo para Sāo Paulo. Săo Paulo. Perspectiva.

\section{FANTIN, Márcia}

(2000) A cidade dividida. Florianópolis, Cidade Futura.

MALLMANN, Regis

(1994) "Florianópolis tem mais miséria que Rio e São Paulo". Folha de São Paulo, 26 de junho de 1994 (Brasil 95, Caderno Especial, p.9).

MAYOL, Pierre

(1996) "Morar". In: CERTEAU, Michel, GIARD, Luce \& MAYOL, Pierre. A invençāo do cotidiano 2: morar, cozinhar. Petrópolis, Vozes, p. 36-185. 